\title{
THE ORIENTATION POLARIZATION IN HEXAGONAL ICE PARALLEL AND PERPENDICULAR TO THE $c$-AXIS
}

\author{
By G. P. Johari and S. J. Jones \\ (Glaciology Division, Inland Waters Directorate, Department of Fisheries and Environment, \\ Ottawa, Ontario $\mathrm{K}_{\mathrm{r}} \mathrm{A}_{\text {oE}}$, Canada)
}

\begin{abstract}
The relative permittivity and loss of zone-refined single crystals of hexagonal ice have been measured in the temperature range $200-271 \mathrm{~K}$ and frequency range $0.5 \mathrm{~Hz}-0.2 \mathrm{MHz}$, using brass, stainless steel, and gold-foil electrodes. The $c$-axis of the crystal was oriented parallel to the electric field in I 4 samples and perpendicular to the field in 8 samples. The equilibrium relative permittivity of orientation polarization $\epsilon_{0}$, parallel and perpendicular to the $c$-axis, is $96.5 \pm \mathrm{I}$ and the average relaxation time $\tau_{\mathrm{av}}$ is $36 \mu \mathrm{s}$ at $265.5 \pm 0.5 \mathrm{~K} ; \epsilon_{0}=124 \pm 1.5$ and $\tau_{\mathrm{av}}=30 \mathrm{~ms}$, at $210 \mathrm{~K}$. The magnitude of the orientation polarization obeys the Curie-Weiss equation with $T_{0}=15 \pm 2 \mathrm{~K}$ for both the orientations. These values are in contrast with the $c .17 \%$ difference in $\epsilon_{0}$ for the two orientations reported in the literature. The extrapolated limiting high-frequency relative permittivity $\epsilon_{\infty}$, measured for both the orientations, is indistinguishable within $0.5 \%$.

The logarithmic plot of the product of $\tau_{\mathrm{av}}$ and temperature against the reciprocal temperature is linear in the range $210^{-2} 21 \mathrm{~K}$ and gives an activation energy and a pre-exponential factor of $51 \pm 2 \mathrm{~kJ} \mathrm{~mol}^{-1}$ and $0.93 \pm 0.22$ ps $\mathrm{K}$ respectively, for both the orientations of the $c$-axis with respect to the electric field. The decrease in activation energy which has been reported to occur in polycrystalline ice and in single crystal ice near $230 \mathrm{~K}$ is not found until a temperature of $210 \mathrm{~K}$. Single crystals of ice stored in the dielectric cell, after the completion of measurements, for periods ranging from $1-11$ weeks at $253 \pm 2 \mathrm{~K}$ showed no change in their $\epsilon_{0}, \tau_{\mathrm{av}}, \epsilon_{\infty}$ that could be attributed to the effect of ageing on the orientation polarization.
\end{abstract}

RÉsumé. Polarisation de la glace Ih parallèlement et perpendiculairement à l'axe $c$. La permittivité relative et le facteur de perte des cristaux de glace hexagonaux obtenus par zone fondue sont mesurés dans un domaine de température comprise entre 200-27 I K, et de fréquence comprise entre $0,5 \mathrm{~Hz}-0,2 \mathrm{MHz}$, en utilisant des feuilles électrode de laiton, d'acier et d'or. Sur I 4 échantillons l'axe $c$ est orienté parallèlement au champ électrique et sur 8 autres, l'axe $c$ est orienté perpendiculairement. La permittivité relative en équilibre, $\epsilon_{0}$, pour ces deux orientations est de $96,5 \pm \mathrm{r}$ et le temps de relaxation moyen, $\tau_{\mathrm{av}}$, est de $36 \mu \mathrm{s}$ à $265,5 \pm 0,5 \mathrm{~K}$. A $210 \mathrm{~K}$, on a $\epsilon_{\mathrm{o}}=\mathrm{r} 24 \pm \mathrm{I}, 5$ et $\tau_{\mathrm{av}}=30 \mathrm{~ms}$. L'intensité de la polarisation en fonction de l'orientation obéit à l'équation de Curie-Weiss avec $T_{0}=15 \pm 2 \mathrm{~K}$ pour les deux orientations. Les valeurs $\epsilon_{0}$ et $\tau_{\mathrm{av}}$ trouvées ci-dessus sont en contradiction avec celles données dans la littérature $\left(\epsilon_{0}\right.$ diffère de $17 \%$ entre les deux orientations). La permittivité relative extrapolée à très haute fréquence, $\epsilon_{\infty}$, obtenue pour les deux orientations est différente seulement de $<0,5 \%$.

Le tracé logarithmique du produit $\tau_{\mathrm{av}} \mathcal{T}$, en fonction de l'inverse de la température, $\mathrm{r} / T$, est linéaire dans le domaine de température $2 \mathrm{IO}^{-2} 2 \mathrm{I} \mathrm{K}$. On trouve ainsi une énergie d'activation de $5 \mathrm{I} \pm 2 \mathrm{~kJ} \mathrm{~mol}^{-1}$ et un facteur préexponentiel de $0,93 \pm 0,22 \mathrm{ps} \mathrm{K}$ pour les deux orientations de l'axe $c$ par rapport au champ électrique. La décroissance de l'énergie d'activation aux alentours de $230 \mathrm{~K}$, qui a été signalée aussi bien dans la glace polycristalline que dans le glace monocristalline n'a pu être observée même jusqu'à 2 ro K. Des mesures complètes de $\epsilon_{0}, \tau_{\mathrm{av}}, \epsilon_{\infty}$ sur des monocristaux de glace conservés dans la cellule diélectrique pendant une période de I à I I semaines à $253 \pm 2 \mathrm{~K}$ montrent que ces valeurs restent inchangées; autrement dit, il n'y a pas eu d'influence du vieillissement quant au rôle de l'orientation de la polarisation.

Zusammenfassung. Die Orientierungspolarisation in hexagonalem Eis parallel und senkrecht zur c-Achse. Die relative Permittivität und der dielektrische Verlust zonengereinigter Einkristalle hexagonalen Eises wurden im Temperaturbereich 200-27I K und im Frequenzbereich $0,5 \mathrm{~Hz}-0,2 \mathrm{MHz}$ gemessen. Es wurden Elektroden aus Messing, rostfreiem Stahl und aus Goldfolien verwendet. Die c-Achse des Kristalls war in 14 Proben parallel zum elektrischen Feld gerichtet und in 8 Proben senkrecht dazu. Die relative Gleichgewichtspermittivität der Orientierungspolarisation, $\epsilon_{0}$, parallel und senkrecht zur $c$-Achse, ist $96,5 \pm \mathrm{I}$ und die mittlere Relaxationszeit $\tau_{\mathrm{av}}$ beträgt $36 \mu \mathrm{s}$ bei $265,5 \pm 0,5 \mathrm{~K}$; bei 2 Io K ist $\epsilon_{0}=124 \pm \mathrm{I}, 5$ und $\tau_{\mathrm{av}}=30 \mathrm{~ms}$. Der Betrag der Orientierungspolarisation folgt einer Curie-Weiss-Gleichung mit $T_{0}=15 \pm 2 \mathrm{~K}$ für beide Kristallrichtungen. Diese Werte stehen im Gegensatz zu den etwa $17 \%$ Unterschied in $\epsilon_{0}$ für die beiden Kristallrichtungen, die in der Literatur angegeben werden. Der extrapolierte Hochfrequenzgenzwert der relativen Permittivität, $\epsilon_{\infty}$, gemessen in beiden Kristallrichtungen, ist innerhalb $0,5 \%$ nicht unterscheidbar.

Das logarithmische Diagramm des Produkts von $\tau_{\mathrm{av}}$ und der Temperatur in Abhängigkeit der reziproken Temperatur ist im Bereich $210-27 \mathrm{I} \mathrm{K}$ linear und gibt eine Aktivierungsenergie von $51 \pm 2 \mathrm{~kJ} \mathrm{~mol}^{-1}$ und einen Exponentialvorfaktor von $0,93 \pm 0,22 \mathrm{ps} \mathrm{K}$ für beide Richtungen der $c$-Achse in bezug zum elektrischen Feld. Eine Abnahme der Aktivierungsenergie, die in vielkristallinem und einkristallinem Eis nahe bei $230 \mathrm{~K}$ eintreten soll, wurde bis herab zur Temperatur von 2 Io K nicht gefunden. Eis-Einkristalle, die nach der Beendigung der Messungen in der dielektrischen Messzelle für Zeitdauern von I-I I Wochen bei $253 \pm 2 \mathrm{~K}$ gelagert wurden, zeigten in ihren $\epsilon_{0}, \tau_{\mathrm{av}}$ und $\epsilon_{\infty}$ keine Veränderung, die einem Alterungseinfluss auf die Orientierungspolarisation zugeordnet werden könnte. 


\section{INTRODUCTION}

It has been held generally that the limiting low-frequency relative permittivity of orientation polarization $\epsilon_{0}$ of hexagonal ice is higher along the $c$-axis than along the $a$ - or $b$-axis. While most workers accept that some difference in $\epsilon_{0}$ along the various axes, which may possibly be caused by the non-equivalence between the energy of the six orientations of a water molecule in ice, might exist at very low temperatures, a controversy remains over the magnitude of the difference at relatively high temperatures.

Humbel and others (1953), who first measured the dielectric properties of single crystals of ice, stated: "The relative difference $\left(\epsilon_{c}-\epsilon_{\perp c}\right) / \epsilon_{c}$ at $\mathrm{I} \mathrm{kc} / \mathrm{sec}$ is about $15 \%$ at $-5^{\circ} \mathrm{C}$, about $12 \%$ at $-20^{\circ} \mathrm{C}$ and about $8 \%$ at $-40^{\circ} \mathrm{C}$ '. Here $\epsilon_{c}$ and $\epsilon_{\perp c}$ represent the relative permittivity along and perpendicular to the $c$-axis, respectively. The difference persisted at lower frequencies, and at $252.6 \mathrm{~K}$ the difference between $\epsilon_{0}$ parallel and perpendicular to the $c$-axis, was 19. Wörz and Cole (1969), who measured the $\epsilon_{0}$ of zone-refined single crystals of ice parallel and perpendicular to the $c$-axis, stated their finding: " $\ldots$ the data [parallel to the $c$-axis] are less reliable but indicate little if any anisotropy of the static dielectric constant near the melting point, rather than a difference of the order of $10 \%$ reported by Humbel, Jona and Scherrer". Here, the "static dielectric constant" refers to $\epsilon_{0}$.

The contribution to the relative permittivity from orientation polarization, $\Delta \epsilon\left(=\epsilon_{0}-\epsilon_{\infty}\right.$, where $\epsilon_{\infty}$ is the limiting high-frequency relative permittivity), in Von Hippel and others' (I97I) results at $253 \pm 0 . \mathrm{I} \mathrm{K}$ for five ice samples measured parallel to the $c$-axis, varied from 99.8 to I 12.6 and for two samples measured perpendicular to the $c$-axis, from 78.8 to 96.4 . At $194.4 \pm 0.3 \mathrm{~K}$, the $\Delta \epsilon$ for the same five samples parallel to the $c$-axis varied from 192 to 243 . From an analysis of their data for various samples, Von Hippel and others (197I) concluded: "With the electric field parallel to the optic axis $(E \| c)$, our best measurements give $\Delta k_{3}=$ I 12.3 at $-20^{\circ} \mathrm{C}$ compared to 96.3 for $E \perp c$. Thus, as to the degree of anisotropy, we are closer to the early data of Humbel, Jona, and Scherrer than Cole-Wörz". In Von Hippel and others' (I97I) notation, $\Delta k_{3} \approx \Delta \epsilon$. Ruepp (I973), who studied zone-refined single crystals of ice in the frequency range $0.5 \mathrm{mHz}-100 \mathrm{kHz}$ and temperature range $103-273 \mathrm{~K}$, stated his conclusion: "An anisotropy of $\epsilon_{\mathrm{S}}-\epsilon_{\infty}$ is possible but it cannot be derived from these [Ruepp's] results'. In Ruepp's (I973) notation, $\left(\epsilon_{\mathrm{s}}-\epsilon_{\infty}\right)=\Delta \epsilon$.

Taubenberger (1973) reported that a sample of ice measured with evaporated gold

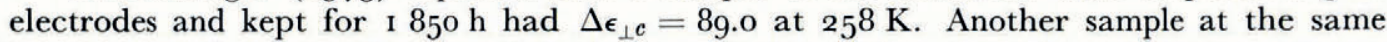
temperature but kept for I $140 \mathrm{~h}$ had $\Delta \epsilon_{\| c}=\mathrm{I} 06.5$. Thus there is a difference of 17.5 between the $\Delta \epsilon$ measured parallel and perpendicular to the $c$-axis at $25^{8} \mathrm{~K}$, which difference is the same as interpolated from Humbel and others' (1953) data. Maeno (1973) measured one sample of ice at $246.7 \mathrm{~K}$ using stainless steel electrodes and reported his finding: "In fig. 27.a, curve A shows the frequency characteristics of dielectric constant of pure ice $(c \|)$, in which dispersion occurs only in a frequency range from $10^{2} \mathrm{~Hz}$ to $5 \times 10^{4} \mathrm{~Hz}$ and the dielectric constant has a constant value of i 10 at lower frequencies". The corresponding value interpolated from Humbel and others' (1953) data is 120.

The theoretical treatment of the orientation polarization within the constraints of the Bernal-Fowler rules (Bernal and Fowler, I933), and the residual entropy of ice of $3.4 \mathrm{I} \pm 0.22$ $\mathrm{J} \mathrm{K}^{-1} \mathrm{~mol}^{-1}$ (Haida and others, 1974), also seems to remain inconclusive on a possible anisotropy of $\epsilon_{0}$. Nagle (1974) in his series expansions of dipolar correlations, which expansions are somewhat different from the ones used by Gobush and Hoeve (1972) and Stillinger and Cotter (1973), stated, "Our series expansions confirm that the anisotropy in $\epsilon_{0}$ is indeed small for the BFP (Bernal-Fowler-Pauling) model. It is now up to the experimentalists to reach agreement on the actual anisotropy". However, Nagle (1974) considers it also possible to explain theoretically a fairly large anisotropy of orientation polarization that would be compatible with the uncertainty of $\pm 0.22 \mathrm{~J} \mathrm{~K}^{-1} \mathrm{~mol}^{-1}$ in the present value of the residual 
entropy of ice. In such a case the Pauling-Slater-Takagi-Bethe type approximation (Nagle, 1974) would need to be made to obtain the $\epsilon_{0}$ of ice parallel and perpendicular to the $c$-axis.

The purpose of this study was to measure accurately the dielectric properties of single crystals of ice with the electric field oriented (i) parallel and, (ii) perpendicular to, the $c$-axis over a frequency and temperature range where reliable values of $\epsilon_{0}$ could be obtained. This paper reports the results of the measurements.

\section{Experimental methods}

\subsection{The electrical equipment}

The equipment used for measurement of capacitance and conductance of ice in the frequency range $0.5 \mathrm{~Hz}$ to $0.2 \mathrm{MHz}$ has been described elsewhere (Johari and Jones, $1976[\mathrm{a}]$ ). The calibration of the instruments was regularly checked to ensure the accuracy of the data which is the same in the present results as in the earlier (Johari and Jones, 1976[a]).

\subsection{The dielectric cells}

All electrical measurements were carried out on disc-shaped ice samples contained in three-terminal dielectric cells with guarded parallel-plate electrodes. One set of electrodes was made of brass and two of stainless steel. For measurements on three samples of ice, two parallel to the $c$-axis and one perpendicular to the $c$-axis, the stainless steel electrodes $E$ and $K$ of the cell shown in Figure I and described below, were covered with gold foil $c$. I $\mu \mathrm{m}$ thick.

Three dielectric cells were used in this study. Two of the dielectric cells, one made of brass and the other of stainless steel, were made to a design similar to McCammon and Work's (1965). This is shown in Figure $\mathrm{I}$. The $12.7 \mathrm{~mm}$ thick, $\mathrm{I}_{5} 2 \mathrm{~mm}$ diameter, plates A and J, and the four $12.7 \mathrm{~mm}$ thick rods c threaded at both ends form a yoke, the top plate of which had a concentric bore of $12.7 \mathrm{~mm}$ diameter. The high electrode $\mathrm{E}, 65 \mathrm{~mm}$ in diameter and

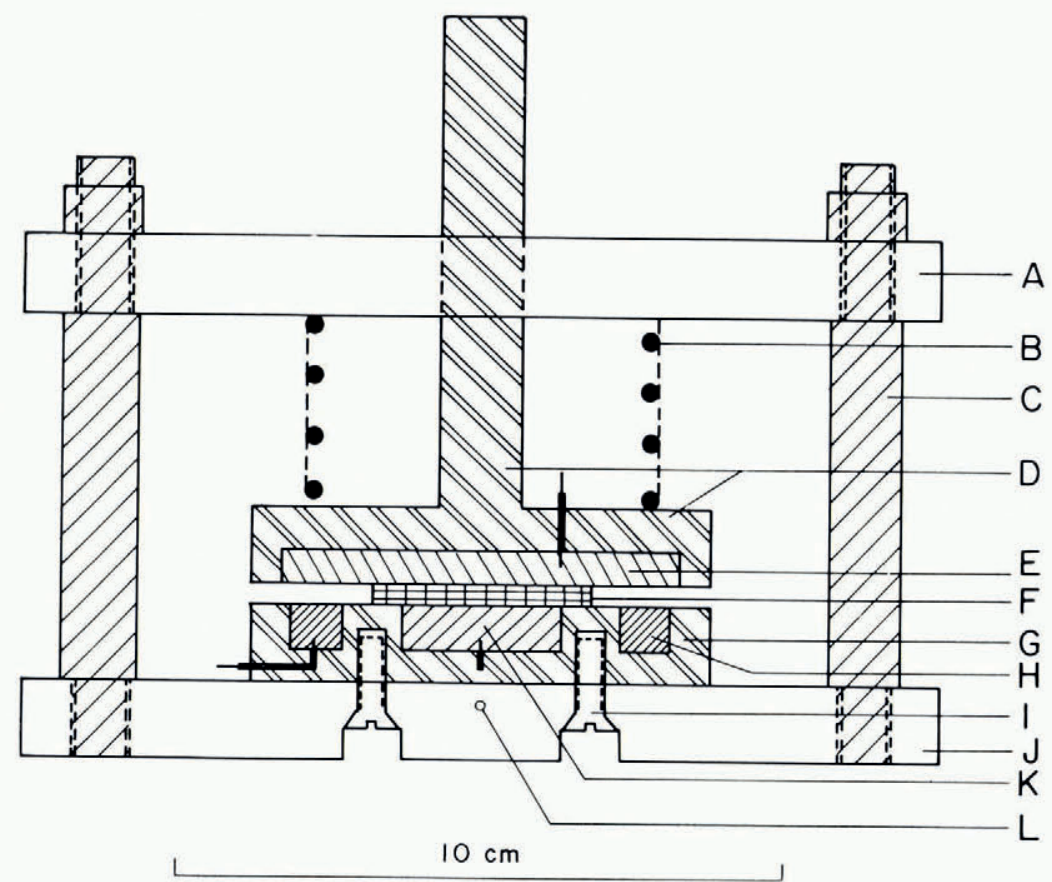

Fig. I. Diagram of the dielectric cell used for the study of single crystals of ice. 
$7 \mathrm{~mm}$ thick, was embedded inside a groove cut out from an inverted mushroom-shaped ground electrode $\mathrm{D}$, whose stem was $12.7 \mathrm{~mm}$ in diameter and $82 \mathrm{~mm}$ long. The lubricated stem slid through the bore in plate A with a clearance of $12.7 \mu \mathrm{m}$. The low electrode $\mathrm{K}, 25.4 \mathrm{~mm}$ in diameter and $7 \mathrm{~mm}$ thick, was embedded in a concentric groove cut out from the disc $\mathrm{G}$, which also received another concentric low electrode $\mathrm{H}$ shaped in the form of a ring, $62 \mathrm{~mm}$ in outer and $44 \mathrm{~mm}$ in inner diameter and $7 \mathrm{~mm}$ thick. $\mathrm{K}$ and $\mathrm{H}$ were $10 \mathrm{~mm}$ apart. G was permanently fixed to the plate $\mathrm{J}$ by means of four screws $\mathrm{I}$, as shown in Figure $\mathrm{I}$. A $2 \mathrm{~mm}$ diameter hole $\mathrm{L}$ was drilled in the plate $\mathrm{J}$ from the circumference to the centre of the plate to receive a thermocouple. $\mathrm{B}$ is a stainless steel spring which maintained an axial load of $\mathrm{I}_{5}^{-20} \mathrm{~kg}$ on a plate $5 \mathrm{~mm}$ thick inserted between $\mathrm{E}$ and $\mathrm{K}$ and thus ensured contact between the ice and electrodes at the various temperatures. The electrodes $\mathrm{E}, \mathrm{H}$, and $\mathrm{K}$ were electrically insulated from the ground electrodes $\mathrm{D}$ and $\mathrm{G}$ by means of mica and water-repellant epoxy cement, and the assemblies DE and GHK were honed to a smooth finish and their faces lapped flat and parallel. The gaps between the guard rings and the electrodes $\mathrm{E}, \mathrm{H}$, and $\mathrm{K}$ were between $0.5^{-0.8} \mathrm{~mm}$. The width of the guard planes were two to three times the thickness of the ice sample F to provide negligible fringing of the electric field. Measurement of $\epsilon_{0}$ of $n$-hexane with this cell showed a stray capacitance of less than $0.1 \%$.

The cell has the advantage of measuring the dielectric properties of a sample without explicit knowledge of the sample thickness. When $\mathrm{D}$ and $\mathrm{G}$ are parallel, the effective air capacitance between $\mathrm{E}$ and $\mathrm{H}$ and $\mathrm{E}$ and $\mathrm{K}$ is given by

$$
C_{\mathrm{K}} / C_{\mathrm{H}}=A_{\mathrm{K}} / A_{\mathrm{H}} \text {, }
$$

where $C_{\mathrm{K}}$ and $C_{\mathrm{H}}$ are the effective air capacitance and $A_{\mathrm{K}}$ and $A_{\mathrm{H}}$ are the area of the electrodes $\mathrm{K}$ and $\mathrm{H}$, respectively. The factor $\left(A_{\mathrm{K}} / A_{\mathrm{H}}\right)$ was determined by placing stainless steel rings between $\mathrm{D}$ and $\mathrm{G}$ which provided an electrode separation in the range $3-7 \mathrm{~mm}$. The value was 2.8936 for brass electrodes and 2.9079 for stainless steel electrodes. The values increased by $c .2 \times \mathrm{IO}^{-4}$ when the temperature was decreased from $295 \mathrm{~K}$ to $223 \mathrm{~K}$ due to a combined effect of a decrease in the area of the electrodes, $\mathrm{K}$ and $\mathrm{H}$ and in the thickness of the steel ring. The air capacitance of an assembly containing a sample of unknown thickness placed on $\mathrm{K}$ can thus be obtained by measuring $C_{\mathrm{H}}$. Since the top electrode $\mathrm{E}$ is supported by the specimen $\mathrm{F}$, the cell has the further advantage of measuring the isobaric expansivity of materials from a knowledge of the change in $C_{\mathrm{H}}$ with temperature (McCammon and Work, 1965).

A third parallel-plate cell made of stainless steel, which was the model Type KMT Guard-ring Capacitor, was commercially available from Rohde and Schwarz, W. Germany. It consisted of an $80.3 \mathrm{~mm}$ diameter low electrode protected by a guard ring. The spacing between the high and low electrodes could be varied up to $9 \mathrm{~mm}$ by means of a micrometer. The gap between the low and the guard electrode was $0.4 \mathrm{~mm}$. The cell has been designed such that an axial load of $8 \mathrm{~kg}$ can be applied to the electrodes in order to maintain an appropriate electrical contact with the sample. For a sample thickness of $6 \mathrm{~mm}$, the cell has an air capacitance of $7.62 \mathrm{pF}$ and a stray capacitance of $0.14 \mathrm{pF}$. The permittivity and loss measured with the cell were corrected for the stray capacitance.

The temperature was measured by means of a calibrated copper-constantan thermocouple which was kept inside the hole $\mathrm{L}$ in plate $\mathrm{J}$ shown in Figure $\mathrm{I}$. The thermocouple was placed under the low electrode in the Type KMT Capacitor. In order to ascertain that the temperature between the plates $\mathrm{E}$ and $\mathrm{K}$ was the same as inside plate $\mathrm{J}$, a thermocouple embedded in felt material $8 \mathrm{~mm}$ thick was kept between $\mathrm{E}$ and $\mathrm{K}$. No difference between the temperature of the two thermocouples was detected in the range 200-295 K.

\subsection{The ice samples and their preparation}

The single crystals of ice were prepared from distilled water contained in polyethylene tubes of $10 \mathrm{~cm}$ internal diameter and I. $1 \mathrm{~m}$ long, by zone-refining in a cold room maintained 
at $263 \pm \mathrm{r}$ K. The treatment of water, the number of passes made during the zone refining, the age of single crystals prior to the study, and the number of samples studied for each orientation are given in Table I.

Table I. Preparation and description of the ice crystals obtained by zone-refining method, and details OF THE SAMPLES AND ELECTRODES USED IN THE STUDY

\begin{tabular}{|c|c|c|c|c|c|c|}
\hline $\begin{array}{l}\text { Laboratory } \\
\text { label }\end{array}$ & $\begin{array}{l}\text { Treatment } \\
\text { of water }\end{array}$ & $\begin{array}{l}\text { Number } \\
\text { of } \\
\text { passes }\end{array}$ & $\begin{array}{l}\text { Duration } \\
\text { of the } \\
\text { passes } \\
\text { months }\end{array}$ & $\begin{array}{l}\text { Age of the } \\
\text { crystal at } \\
\text { the time } \\
\text { of study } \\
\text { years }\end{array}$ & $\begin{array}{l}\text { Number of samples } \\
\text { measured parallel } \\
\text { to the c-axis and the } \\
\text { electrodes used }\end{array}$ & $\begin{array}{l}\text { Number of samples } \\
\text { measured perpendicular } \\
\text { to the c-axis and the } \\
\text { electrodes used }\end{array}$ \\
\hline$D_{1}$ & $\begin{array}{l}\text { de-ionized and } \\
\text { boiled }\end{array}$ & I & 3 & $2.3 \pm 0.2$ & I (gold); 2 (steel) & I (brass) \\
\hline $\mathrm{D}_{2}$ & $\begin{array}{l}\text { de-ionized and } \\
\text { boiled }\end{array}$ & 2 & 5 & $1.5 \pm 0.2$ & I (brass); I (steel) & I (steel); I (gold) \\
\hline MPI & millipore filtered & I & 4 & $1.2 \pm 0.3$ & 2 (brass); I (gold) & I (brass); 2 (steel) $\dagger$ \\
\hline $\mathrm{DF}_{\mathrm{I}}$ & $\begin{array}{l}\text { millipore filtered, } \\
\text { de-ionized and } \\
\text { boiled }\end{array}$ & 3 & 9 & $2.0 \pm 0.2$ & I (brass); I (steel) $\dagger$ & I (steel) $\dagger$ \\
\hline $\mathrm{DF}_{2}$ & $\begin{array}{l}\text { millipore filtered and } \\
\text { de-ionized }\end{array}$ & 3 & Io & г. $8 \pm 0.3$ & 2 (steel) & \\
\hline $\mathrm{ZR}_{\mathrm{I}} *$ & de-ionized & I & 3 & $8 \pm I$ & I (brass) & \\
\hline $\mathrm{ZR}_{2} *$ & de-ionized & I & 3 & $8 \pm \mathbf{I}$ & I (steel) & I (brass) \\
\hline
\end{tabular}

* Prepared by Dr R. O. Ramseier at the U.S. Cold Regions Research and Engineering Laboratory, Hanover, N.H., U.S.A.

† Samples studied with Type KMT Capacitor.

The crystallographic axis of the $60-70 \mathrm{~mm}$ thick cylindrical sample of ice was first determined using crossed polarizing filters. In nearly all crystals the $c$-axis lay perpendicular to the cylindrical axis of the single crystals. The cylindrical sample was then cut with a band saw to machinable dimensions with a suitably oriented $c$-axis. Finally, the discs of ice from different stocks, $3-6 \mathrm{~mm}$ in thickness and $28-30 \mathrm{~mm}$ in diameter, were cut on a lathe. Disc samples of the same diameter but $c .2 \mathrm{~mm}$ thickness were also cut from the same stock, and at least one sample from each stock was used for accurately determining the direction of the $c$-axis by means of X-ray diffraction, prior to making the electrical measurements. The X-ray measurements showed that the $c$-axis of the disc sample lay within $0.5^{-2}{ }^{\circ}$ of the desired direction. Two samples were also examined by X-ray diffraction after they had been taken out of the dielectric cell to ensure that the $c$-axis orientation had not altered, and nearly all samples were examined after the completion of electrical measurements with crossed polarizing filters to ensure the single crystallinity of the ice. No change in the $c$-axis orientation or in crystallinity was found in samples which were stored in the dielectric cell for as long as two months at $25^{8} \pm 2 \mathrm{~K}$ under a uniaxial stress.

The ice samples used with the Type KMT Capacitor were $85-90 \mathrm{~mm}$ in diameter and c. $6 \mathrm{~mm}$ in thickness. Two samples with the $c$-axis perpendicular to the electric field and one sample with the $c$-axis parallel to the electric field were studied with this capacitor and the rest of the samples were studied with the cell shown in Figure I.

The dielectric cell containing the ice sample was placed in a polyethylene bag, the leads were taken out and the bag closed. The entire assembly was kept inside a thermostatically air-cooled refrigeration unit capable of cooling to a temperature of $199 \mathrm{~K}$. In several experiments, two cells containing the ice samples, having either the same or different $c$-axis orientations, were kept in the cold chamber. Measurements could thus be made on several samples at identical temperatures after thermal equilibrium was reached. The temperature of the cells 
remained constant to within $\pm 0.05 \mathrm{~K}$ for $2-3 \mathrm{~h}$. Therefore, there is little uncertainty in the values derived from our measurements of capacitance and conductance, which might otherwise exist from any variation in the temperature of the ice sample during the period of the frequency scan.

\section{SOURGeS OF ERROR}

In order to ascertain the reliability of our results, it is important to discuss the possible errors in our measurements, and the consequent effect of such errors on the quantities derived. An error in the air capacitance $C_{\mathrm{K}}$ corresponding to a given thickness of the ice sample contained in an enclosed dielectric cell, may be caused if the ice sublimed and redeposited on the faces $\mathrm{H}$ and $\mathrm{E}$ in Figure $\mathrm{I}$. Since $C_{\mathrm{K}}$ is calculated from the ratio $\left(A_{\mathrm{K}} / A_{\mathrm{H}}\right)$ and the value of $C_{\mathrm{H}}$, both measured in air, an increase in $C_{\mathrm{H}}$ caused by a thin deposit of ice on $\mathrm{H}$ and $\mathrm{E}$ would give an apparently high value of $C_{\mathrm{K}}$ and consequently a low value of the relative permittivity and loss. A sample of ice was kept in the dielectric cell enclosed in a polyethylene bag and $C_{\mathrm{H}}$ was measured with time. No increase in $C_{\mathrm{H}}$ was found over a period of seven weeks. So, the errors due to a possible sublimation of ice are too small to be detectable.

A major error in the value of $\epsilon_{0}$ would be caused by the air gap between ice and the electrodes if the faces of the ice sample were not flat and parallel, or if one or both faces were convex. Although annealing of ice under a load of $\mathrm{I}^{-20} \mathrm{~kg}$ at $268 \mathrm{~K}$ for $4^{-5} \mathrm{~d}$ may sufficiently deform the ice and thus reduce the air gaps, it was necessary to ensure that such an air gap did not exist. Therefore, after measurements on a sample of ice had been made at a few temperatures, the dielectric cell containing the ice was immersed in $n$-hexane at $268 \mathrm{~K}$, and measurement of capacitance and conductance made again at several frequencies between $\mathbf{0 .} \mathbf{I}-5 \mathrm{kHz}$. If immersion of the dielectric cell in $n$-hexane caused an increase in the measured values of capacitance and conductance, the ice sample and all the data obtained on it were rejected. The data given here are only for those samples whose values of capacitance and conductance remained unaltered when the ice was surrounded by $n$-hexane.

Air between the ice and electrodes can also be entrapped if the faces of the discs of ice are concave. Such air gaps cannot be detected by the above procedure, because ice around the air gap would seal the gap from the outside. This may also cause a significant error in our data. From Davidson and Wilson's ( 1963 ) formulae for the effect of air gaps on the dielectric properties, we calculate that a uniform air gap of $\mathrm{I} \mu \mathrm{m}$ for a $5 \mathrm{~mm}$ thick sample of ice would give values of $\epsilon_{0}$ and relaxation time $2 \%$ lower, and of $\epsilon_{\infty} 0.07 \%$ lower, than the true values. It is conceivable that an air gap of $<\mathrm{I} \mu \mathrm{m}$ could exist in some of our assembled electrodes containing ice, although our experience with the reproducibility of $\mathrm{I} \%$ in the $\epsilon_{0}$ values for the same sample of ice, suggests that the error due to such an air gap is indistinguishable from the overall errors in the estimate of $\epsilon_{0}$. Furthermore, since an error due to the presence of such an air gap, could occur with equal probability in samples of both the orientations, we feel certain that such an error would not affect our conclusions concerning the anisotropy of $\epsilon_{0}$ in ice.

Possible errors in the capacitance and conductance measurement have already been discussed (Johari and Jones, I976[a]) and those in the temperature were given in the preceding section. Errors due to both sources are less than $0.2 \%$ in $\epsilon_{0}$.

\section{Results AND Discussion}

\section{I. The frequency dependence of $\epsilon^{\prime}$ and $\epsilon^{\prime \prime}$}

The relative permittivity $\epsilon^{\prime}$ and loss $\epsilon^{\prime \prime}$ of ice, measured within $2 \mathrm{~h}$ of sample preparation, exceeded 250 and 200 , respectively at $0.1 \mathrm{kHz}$ and $268 \mathrm{~K}$. The values decreased rapidly with time and a typical complex-plane plot of $\epsilon^{\prime \prime}$ against $\epsilon^{\prime}$ followed the pattern indicated in Figure 2. In nearly all cases, $\epsilon^{\prime \prime}$ decreased to a value of 4 or lower at $268 \mathrm{~K}$ in $6 \mathrm{o}-8 \mathrm{o} \mathrm{h}$. 


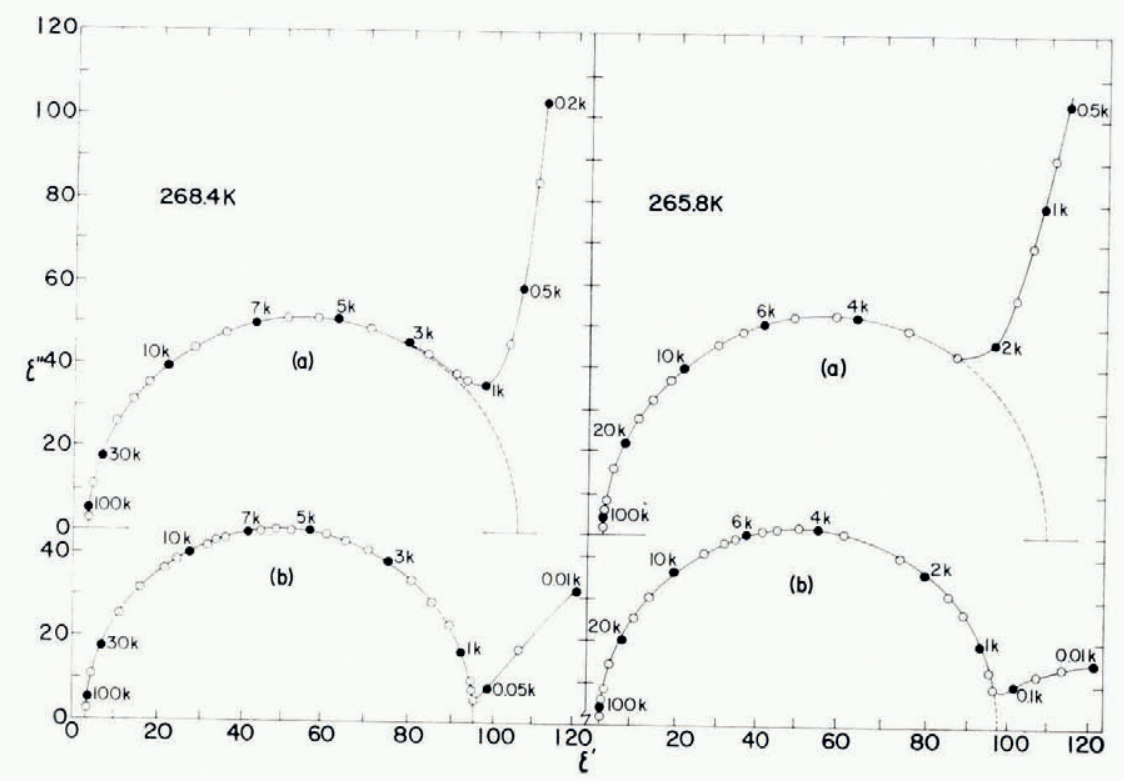

Fig. 2. The change in the shape of the complex-plane plots of the relative permittivity and loss of an ice sample measured paralle to the c-axis. Left half: measured at $268.4 \mathrm{~K},(a)$ after $48 \mathrm{~h},(\mathrm{~b})$ after $70 \mathrm{~h}$. Right half: measured at $265.8 \mathrm{~K},(a)$ after $49 \mathrm{~h},(b)$ after the application of $2.1 \mathrm{kV} \mathrm{cm}^{-1}$ electric field along the c-axis for $1.8 \mathrm{~h}$. The numbers besides the filled data points are frequencies in hertz.

Measurements at low temperatures were made only after the value of $\epsilon^{\prime \prime}$ at $0 . \mathrm{I} \mathrm{kHz}$ was less than 4 at $268 \mathrm{~K}$. In most cases, after the completion of the low-temperature measurement, which took 4-8 d, the sample when measured again at $0 . \mathrm{I} \mathrm{kHz}$ had $\epsilon^{\prime \prime}<3$ at $268 \mathrm{~K}$. The annealing of the ice was found to be most effective in reducing its $\epsilon^{\prime \prime}$ to a limiting value when done at temperatures close to $270 \mathrm{~K}$. Therefore, all ice samples were stored in a cold room maintained at $268 \pm \mathrm{I} \mathrm{K}$, when not being measured. A similar observation was reported by Taubenberger (1973).

The $\epsilon^{\prime \prime}$ of ice at $0.1 \mathrm{kHz}$ and $266 \mathrm{~K}$ was also found to decrease when an electric field of c. $2 \mathrm{kV} \mathrm{cm}^{-1}$ was applied for $\mathrm{I}-2 \mathrm{~h}$. After removal of the field the value of $\epsilon^{\prime \prime}$ remained constant for nearly Io min and then began to increase with time. The behaviour, which seems typical of ice (Gränicher and others, 1955; Von Hippel and others, 1971) and of clathrate hydrates (Wilson and Davidson, I963; Davidson and Wilson, 1963 ), is shown in Figure 2. While the application of a d.c. voltage for a period of $2 \mathrm{~h}$ sufficiently reduced the $\epsilon^{\prime \prime}$ of ice to obtain reliable values of its $\epsilon_{0}$, the increase in $\epsilon^{\prime \prime}$ with time after removal of the field made the measurements somewhat uncertain. The reduction in $\epsilon^{\prime \prime}$ at low frequencies on the application of a d.c. voltage suggests that slow build-up of space charge, arising either from the irreversibility of the electrode material to protons, or from the presence of ions (Davidson and Wilson, 1963) in ice, is responsible for higher values of $\epsilon^{\prime \prime}$ than anticipated from the orientation polarization alone.

The $\epsilon^{\prime}$ and $\epsilon^{\prime \prime}$ of ice are plotted in a complex plane at several temperatures in Figure 3 . In the temperature range of study both the low- and high-frequency part of the arc could be well defined, and, as evident in Figure 3 , the plots intersect the $\epsilon^{\prime}$ axis very nearly vertically. With decreasing temperature, the plots depart progressively from a semicircle, although for temperatures above $250 \mathrm{~K}$ the plots are semicircular and are indistinguishable from a Debyetype process with a single relaxation time. This feature is clearly seen in Figure 4 in which the 


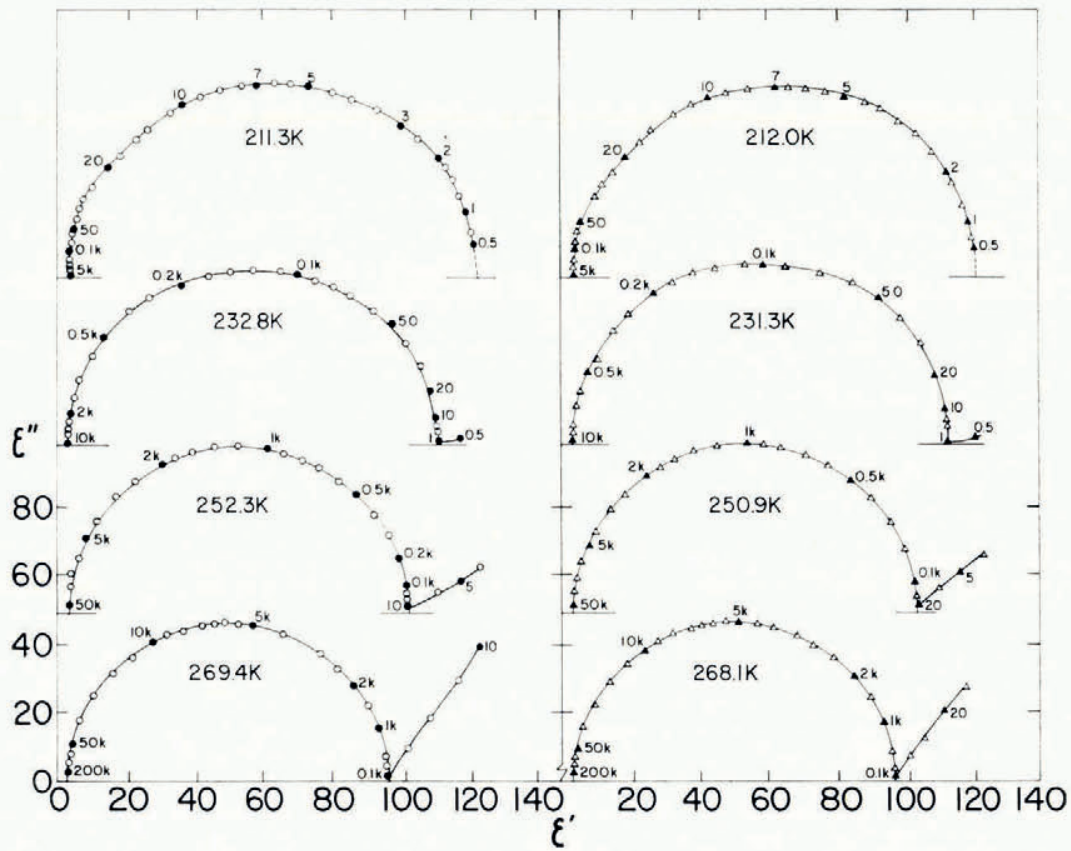

Fig. 3. Complex-plane plots of the relative permittivity and loss of ice at several temperatures. The left half is for measurement with the c-axis oriented parallel to the electric field and the right half for that oriented perpendicular to the field. The numbers besides the filled data points are frequencies in hertz. The plots have been progressively shifted upwards as indicated by the axis.

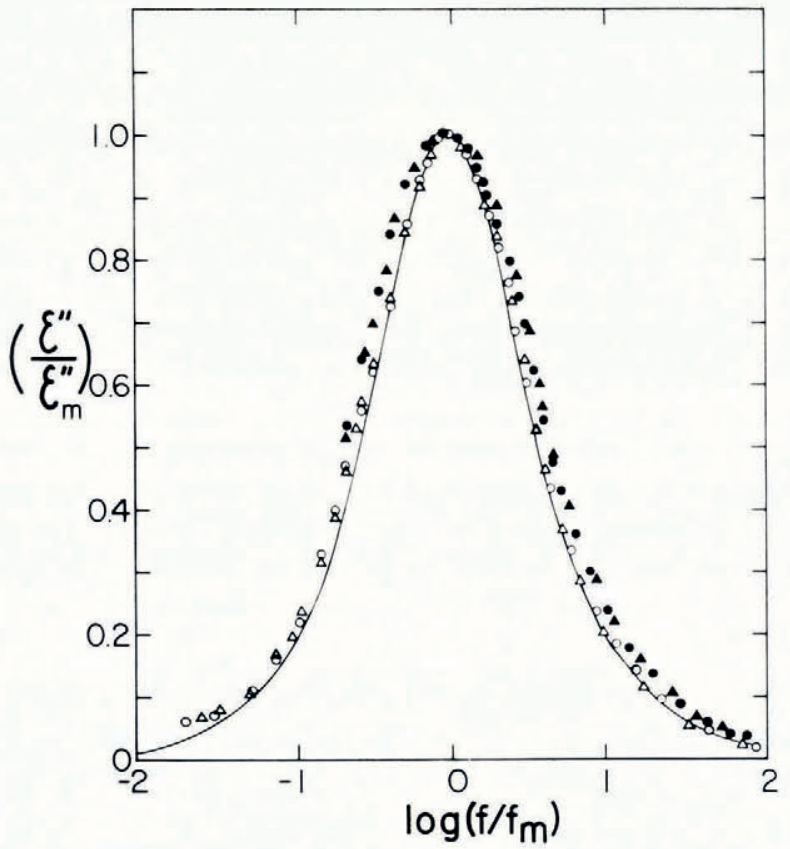

Fig. 4. Normalized plots of the dielectric loss of ice against frequency at several temperatures. The solid line is the theoretical curve for a Debye-type relaxation. $\bigcirc$, parallel to the c-axis at $238.1 \mathrm{~K}$ and $\mathrm{O}$, at $20 \mathrm{I.5} \mathrm{K}$. $\triangle$, perpendicular to the c-axis at $235.9 \mathrm{~K}$ and $\mathbf{\Delta}$, at $202.6 \mathrm{~K}$. 
normalized dielectric loss $\epsilon^{\prime \prime} / \epsilon^{\prime \prime}{ }_{m}$ of one sample of ice of each orientation is plotted against $f / f_{\mathrm{m}}$ on a logarithmic scale. Here $\epsilon_{\mathrm{m}}{ }^{\prime \prime}$ is the maximum loss and $f_{\mathrm{m}}$ the frequency of maximum loss. The solid line represents a Debye-type absorption with a single relaxation time.

The half-width of the normalized plots at temperatures $<230 \mathrm{~K}$ varied from one sample to another. Therefore, no further analysis of the frequency dependence of $\epsilon^{\prime}$ and $\epsilon^{\prime \prime}$ into several dispersion regions was attempted. The ambiguity of such an analysis has already been discussed in the literature (Gough and others, I973; Johari and Jones, 1976) and it is not certain whether the increase in the half-width of the plots with decreasing temperatures is due to an increase in the relative amplitude of several Debye-type relaxations or to an increase in the relative magnitude of the limits of relaxation time representing a distribution. At temperatures near $205 \mathrm{~K}$, the approach of $\epsilon^{\prime \prime}$ towards the axis at high frequencies indicated the presence of a small relaxation region, similar to the one seen in $\mathrm{D}_{2} \mathrm{O}$ ice (Johari and Jones, 1976). A similar high-frequency relaxation region has also been observed in $\mathrm{H}_{2} \mathrm{O}$ ice single crystals by Von Hippel and others (197I), and Ruepp (1973) at kilohertz frequencies but a temperatures below $240 \mathrm{~K}$ and $200 \mathrm{~K}$, respectively, and by Johari (1976) at megahertz frequencies at temperatures above $250 \mathrm{~K}$.

\subsection{The equilibrium relative permittivity}

The equilibrium relative permittivity $\epsilon_{0}$ was obtained from a graphical extrapolation of the low-frequency end of 86 plots for samples with the $c$-axis oriented parallel to the electric field and 6 I plots for samples with the $c$-axis oriented perpendicular to the electric fields. Strictly, $\epsilon^{\prime}=\epsilon_{0}$, when $\epsilon^{\prime \prime}=0$. For ice, and for many other solids, this condition is not observed because space-charge and other non-linear polarizations begin to contribute to $\epsilon^{\prime \prime}$ at frequencies far above the one at which $\epsilon^{\prime \prime}$ due to orientation polarization would become zero. Within the reproducibility of $\pm 2 \%$, our values of $\epsilon_{0}$ are not likely to be different from the

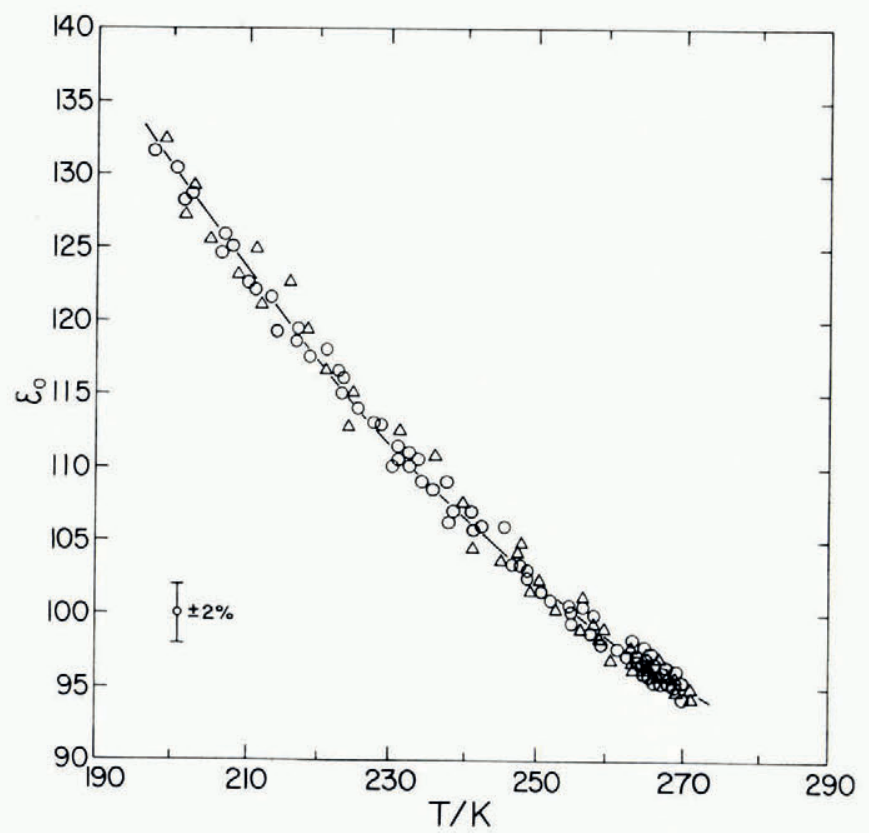

Fig. 5. The variation of the equilibrium relative permittivity of ice with temperature; $\bigcirc$, parallel to the c-axis; $\triangle$, perpendicular to the c-axis. 
TABle II. EQuilibrium Relative PERmittivity and RElaxation time of HEXAGONAL ICE NEAR $266 \mathrm{~K}$ FOR THE TWO ORIENTATIONS

\begin{tabular}{|c|c|c|c|}
\hline Orientation of the ice crystal within $\pm 2^{\circ}$ & $\begin{array}{c}\text { Temperature } \\
\mathbf{K}\end{array}$ & $\epsilon_{0}$ & $\begin{array}{c}\tau_{\mathrm{av}} \\
\mu \mathrm{s}\end{array}$ \\
\hline$c$-axis parallel to the electric field & $\begin{array}{l}265.9 \\
265.6 \\
265.9 \\
266.1 \\
265.4\end{array}$ & $\begin{array}{l}96.8 \\
96.3 \\
96.9 \\
95.7 \\
96.9\end{array}$ & $\begin{array}{l}35.5 \\
36.5 \\
36.4 \\
36.8 \\
38.0\end{array}$ \\
\hline$c$-axis perpendicular to the electric field & $\begin{array}{l}265.9 \\
265 \cdot 1 \\
265.8 \\
265.7 \\
265.7\end{array}$ & $\begin{array}{l}96.3 \\
95.8 \\
96.1 \\
96.3 \\
95.8\end{array}$ & $\begin{array}{l}35.8 \\
35.0 \\
36.2 \\
36.2 \\
35.1\end{array}$ \\
\hline
\end{tabular}

true $\epsilon_{0}$, although the condition $\epsilon^{\prime \prime}=0$ was not satisfied by any set of our measurements. The $\epsilon_{0}$ of ice for both the orientations is plotted in Figure 5 , and values near $266 \mathrm{~K}$ for five different samples are given in Table II.

The $\epsilon_{0}$ measured parallel to the $c$-axis at $248 \mathrm{~K}$ and $268 \mathrm{~K}$ are 103 and 96 respectively. The corresponding values interpolated from Humbel and others (I953) are I20 and II3, from Von Hippel and others (I97I) are I 8 and I06, and from Taubenberger (1973) for his BI4 sample are II 3 and I06. Thus there is a considerable difference between our $\epsilon_{0}$ measured parallel to the $c$-axis and those given in the literature. While the scatter in $\epsilon_{0}$ values, already mentioned in Section $\mathrm{I}$, in Von Hippel and others' (I97 I) data, may account for some degree of difference, the reasons for a difference between our data and those of Humbel and others (1953) and Taubenberger (1973) are not obvious. Our values agree with Wörz and Cole's ( 1969 ) values in which the errors in $\epsilon_{\mathrm{o}}$ from space-charge polarization and "d.c. conductivity" were largely eliminated.

The value of $\epsilon_{0}=96$, measured perpendicular to the $c$-axis at $268 \mathrm{~K}$, agrees with the values reported by Humbel and others (1953), by Wörz and Cole (1969), by Von Hippel and others (197I) and by Taubenberger (1973), within their respective uncertainty, which Humbel and others (I953) quoted for their $\epsilon^{\prime}$ values, ". . . ist deshalb von der Grössenordnung $3,5-4,5 \% "$ ".

For a given sample of ice, our $\epsilon_{0}$ values showed a scatter from a mean line of less than $\pm 0.7 \%$. The scatter increased when $\epsilon_{0}$ of several different samples was plotted on the same figure. In all cases of $\mathrm{I} 4$ samples measured parallel to the $c$-axis and 8 measured perpendicular to the $c$-axis, the departure of the data from a mean line did not exceed $2 \%$, as indicated in Figure 5. We attribute the apparent uncertainty in $\epsilon_{0}$ to the possible non-parallel faces of the sample, as discussed in Section 3 , or the nature of ice itself. Within this uncertainty, the $\epsilon_{0}$ measured parallel to the $c$-axis is the same as that measured perpendicular to the $c$-axis as the data in Table II and Figure 5 indicate.

The $\epsilon_{0}$ values were fitted to the Curie-Weiss equation,

$$
\epsilon_{0}-\epsilon_{\infty}=\frac{A}{T-T_{\mathrm{o}}},
$$

where $\epsilon_{\infty}$ is the limiting high-frequency permittivity of the orientation polarization, $T$ is the absolute temperature, and $A$ and $T_{0}$ are empirical constants. The values of $A$ and $T_{0}$ obtained, assuming $\epsilon_{\infty}=3.2$, for ice for the two orientations and for all samples and orientations, are given in Table III, and a plot of $\left(\epsilon_{0}-\epsilon_{\infty}\right)^{-1}$ against temperature is shown in Figure 6. The standard deviation of $A$ and $T_{0}$ and of the data points obtained from a least-square treatment are also included. The agreement between $A$ and $T_{0}$ for the two orientations indicates the consistency of our measured values for different samples. Our $A$ and $T_{0}$ values in Table III 
differ from those given by Wörz and Cole (1969), who found $A=207$ I $5 \mathrm{~K}$ and $T_{0}=3^{8} \mathrm{~K}$, and from those obtained from Von Hippel and others' (1971) plots, where the values of $A$ for the two orientations differ considerably, but the $T_{0} \mathrm{~s}$ are close to o $\mathrm{K}$. The values of $A$ and $T_{\mathrm{o}}$ are very sensitive to changes in the input data, and probably have little significance except for the purpose of interpolation.

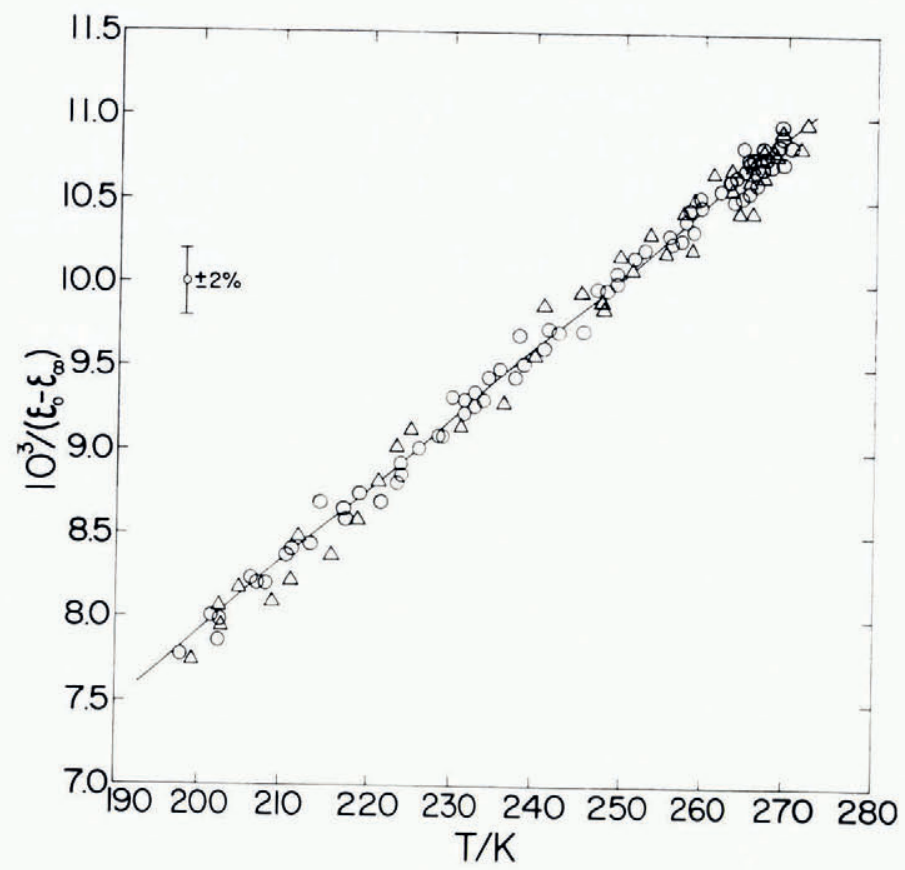

Fig. 6. The variation of $\left(\epsilon_{0}-\epsilon_{\infty}\right)^{-1}$ with temperature for ice; $\bigcirc$, parallel to the c-axis; $\triangle$, perpendicular to the c-axis.

Table III. The empirical constants of the Curie-Weiss equation, and the pre-Exponential factor and ACTIVATION ENERGY CALCULATED FROM EYRING'S EQUATION FOR HEXAGONAL ICE FOR THE TWO ORIENTATIONS

\section{Orientation}

$c$-axis parallel to the electric field $c$-axis perpendicular to the electric field combined data for both orientations

\begin{tabular}{|c|c|c|c|c|c|}
\hline $\begin{array}{l}A \\
\mathrm{~K}\end{array}$ & $\begin{array}{l}\mathcal{T}_{\mathrm{o}} \\
\mathrm{K}\end{array}$ & $\begin{array}{c}\text { Standard } \\
\text { deviation } \\
\times 10^{-1}\end{array}$ & $\begin{array}{c}\tau_{0} \\
\operatorname{ps~K}\end{array}$ & $\begin{array}{c}E^{\star} \\
\mathrm{kJ} \mathrm{mol}^{-1}\end{array}$ & $\begin{array}{l}\text { Standard } \\
\text { deviation }\end{array}$ \\
\hline $23490 \pm 200$ & $14 \pm 2$ & 0.69 & $2.3 \pm 3.4$ & $49.4 \pm \mathbf{2 . 5}$ & 0.33 \\
\hline $23260 \pm 400$ & $16 \pm 4$ & I. IO & $0.23 \pm 0.14$ & $53.9 \pm 0.8$ & 0.08 \\
\hline $23400 \pm 200$ & $15 \pm 2$ & 0.87 & $0.93 \pm 0.22$ & $51.1 \pm 1.6$ & 0.27 \\
\hline
\end{tabular}

The uncertainty in $A, T_{0}, \tau_{0}$, and $E^{\star}$ is the standard error from a least-square fit of the data plotted as in Figures 6 and 8 . The standard deviation also refers to the relevant plots.

From the recent discussion (Hollins, 1964; Rahman and Stillinger, 1972; Gobush and Hoeve, 1972; Stillinger and Cotter, 1973; Nagle, 1974) of the theoretical treatment of the orientation polarization in ice, there is little agreement between the various workers on the choice of dipolar interactions that affect the $\epsilon_{0}$ of ice. Consequently, it is not certain whether the short-range interactions, within the constraints of Bernal-Fowler rules (Bernal and Fowler, 1933) and Pauling's (1935) calculation of residual entropy, used by Onsager and Dupuis (1962) and later by Nagle (I974), should be used in calculating the $\epsilon_{0}$, or whether the long-range interactions as in Kirkwood's theory (1940) for solids, or only short-range interactions, as in Kirkwood's theory (r939) for liquids, would be more appropriate. 
Nagle (1974) has proposed that $\epsilon_{0}$ of ice is likely to be isotropic, on the theoretical grounds mentioned above, and the equation of Onsager and Dupuis (1962) can be written in the form:

$$
\epsilon_{0}-\epsilon_{\infty}=4 \pi \mathcal{N} \mu^{2} G / 3 V k T,
$$

where $G$ is defined as the polarization factor, $\mathcal{N}$ is Avogadro's number, $\mu$ is the dipole moment of a water molecule in ice, $V$ is the molar volume, $k$ is the Boltzmann factor, and $T$ is the temperature. Nagle (1974) calculated $G=3$. The Kirkwood-Fröhlich (Fröhlich, 1949) equation, which takes account of short-range interactions, is

$$
\epsilon_{0}-\epsilon_{\infty}=\left[3 \epsilon_{0} /\left(2 \epsilon_{0}+\epsilon_{\infty}\right)\right]\left(4 \pi N m^{2} \mu_{0}^{2} g / 3 V k T\right),
$$

where $g$ is the orientational correlation factor, which is a measure of the extent to which hindered rotation of neighbouring molecules tends to align their dipolar orientations, $m$ is a measure of the enhancement of the dipole moment by its own reaction field, and $\mu_{0}$ is the dipole moment of a water molecule in the vapour state, according to Clough and others (1973), $\mu_{0}=$ I.855.

From a comparison of Equations (2) and (3), $G$ and $g$ are formally related by,

$$
\mu^{2} G=\left[3 \epsilon_{0} /\left(2 \epsilon_{0}+\epsilon_{\infty}\right)\right] m^{2} \mu_{0}^{2} g .
$$

Since $\epsilon_{0} \gg \epsilon_{\infty}$ for ice, Equation (4) becomes

$$
\mu^{2} G=\mathrm{I} .5^{m^{2}} \mu_{\mathrm{o}}^{2} g .
$$

In contrast to $\mu_{0}, \mu$ is not accessible to direct measurement. It is noteworthy that if $g=2.07$ (Rahman and Stillinger, 1972) and $G=3$ (Nagle, 1974) are substituted in Equation (4), $\mu$ becomes approximately equal to $m \mu_{0}$. From Equation (2) the dipole moment of a water molecule $\mu=2.97 \times \mathrm{IO}^{-18}$ e.s.u. at $243 . \mathrm{I} \mathrm{K}$, which gives the charge associated with a Bjerrum defect (Bjerrum, I95 I ), $q=\mathrm{I} .87 \times \mathrm{IO}^{-10}$ e.s.u. $\left(6.25 \times \mathrm{IO}^{-20} \mathrm{C}\right)$. This value is close to that estimated by Onsager and Dupuis (1962).

In Equation (3), $m$ is given by either $\left(\epsilon_{\infty}+2\right) / 3$ or $\left(n^{2}+2\right) / 3$, where $n$ is the refractive index at optical frequencies. There has been a considerable discussion (Hollins, 1964; Chan and others, 1965; Johari and Jones, I976) as to which of the two quantities $\epsilon_{\infty}$ or $n^{2}$ is appropriate in the calculation of $m$ and some ambiguity still remains as to the frequency at which the orientation polarization separates from the distortion polarization. From Figures 5 and 7

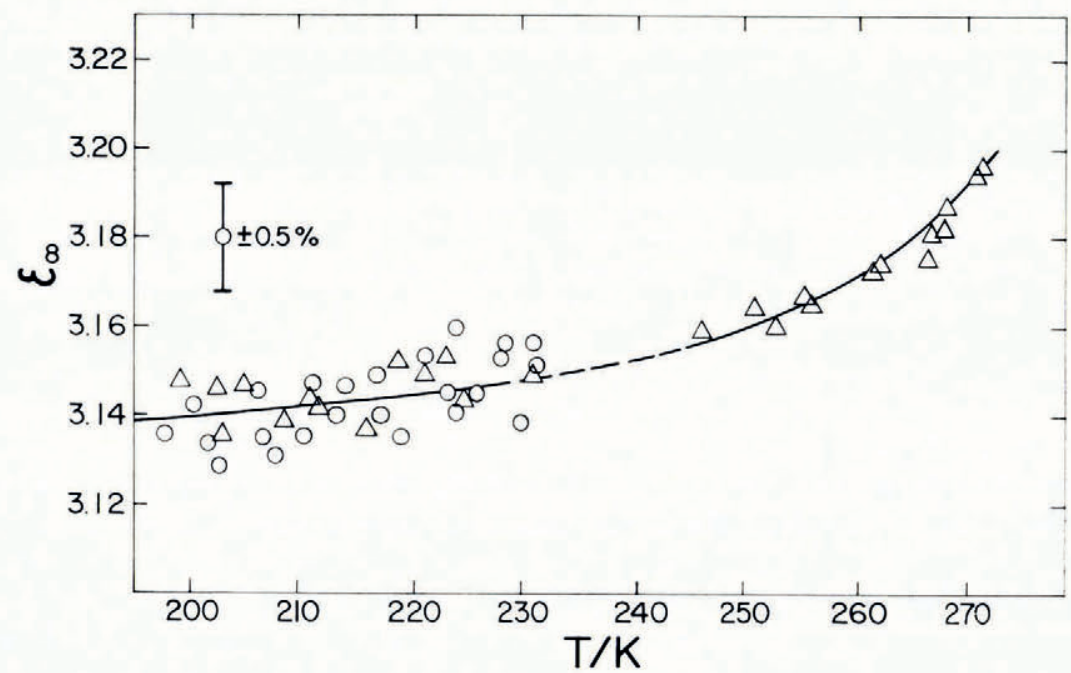

Fig. 7. The limiting high-frequency relative permittivity plotted against temperature; $\bigcirc$, parallel to the c-axis, and $\triangle$, perpendicular to the c-axis. The data points above $240 \mathrm{~K}$ are from Johari (1976). 
$\epsilon_{0}=105.2$ and $\epsilon_{\infty}=3.15$ for both the orientations in ice at $243 \mathrm{~K}$. Using Equation (3), one obtains $g=\mathrm{I} .78$, if $m=\left(\epsilon_{\infty}+2\right) / 3$, and $g=3.40$, if $m=\left(n_{\mathrm{D}^{2}}+2\right) / 3$ using the refractive index $n_{\mathrm{D}}$ for sodium D light. Evidently the $g$ calculated assuming $m=\left(\epsilon_{\infty}+2\right) / 3$ is close to the theoretical value of 2.07 calculated by Rahman and Stillinger (I972) for ice containing 2048 molecules using a Monte-Carlo procedure. We have arrived at a similar conclusion from a somewhat different consideration in the case of $\mathrm{D}_{2} \mathrm{O}$ ice (Johari and Jones, $1976[\mathrm{~b}]$ ).

Another consideration concerning the choice between $\epsilon_{\infty}$ and $n^{2}$ in calculating $m$ would be useful here. If the $\left(\epsilon_{0}-\epsilon_{\infty}\right)$ of ice obeyed Curie's law, i.e. if $T_{0}=0 \mathrm{~K}$ in Equation (I), as Ruepp and Käss (I969), Von Hippel and others (197I), Ruepp (I973), and Johari and Whalley (1973) have found, a comparison of Equation (I) with Equation (2) gives

$$
A=4 \pi \mathcal{N} \mu^{2} G / 3 V k \quad\left(\text { if } T_{\mathrm{o}}=\mathrm{o} \mathrm{K}\right) .
$$

Since $\epsilon_{0} \gg \epsilon_{\infty}$ for ice, the first term on the right-hand side of Equation (3) becomes I.5, and then from a comparison of Equations (I) and (3),

$$
A=2 \pi N m^{2} \mu_{0}^{2} g / V k \quad\left(\text { if } T_{0}=o \mathrm{~K}\right) \text {. }
$$

The molar volume of ice, $V$, decreases from $19.66 \mathrm{~cm}^{3} \mathrm{~mol}^{-\mathrm{I}}$ at $273 \mathrm{~K}$ to $19.45 \mathrm{~cm}^{3} \mathrm{~mol}^{-\mathrm{I}}$ at $200 \mathrm{~K}$ (Lonsdale, 1958) and $G$ and $g$ remain constant. It follows, then, that $A$ can be constant only if $\mu^{2}$ and $m^{2}$, in Equations (6) and (7) respectively, decrease with temperature in the same proportion as the molar volume. Such a decrease in $\mu^{2}$ is implicit in Equations (2) and (6), via the temperature dependence of the $\mathrm{O}-\mathrm{O}$ distance $d$, which determines the charge $q$ associated with a Bjerrum defect by $q=3^{\frac{1}{2}} \mu / d$, if $q$ is assumed to remain constant with temperature. The decrease in $\mathrm{O}-\mathrm{O}$ distance corresponding to the above-mentioned decrease in $V$ is from $2.76 \AA$ at $273 \mathrm{~K}$ to $2.75 \AA$ at $200 \mathrm{~K}$ (Lonsdale, r 958).

The term $m$ in Equations (3) and (7) is temperature dependent via the temperature dependence of $\epsilon_{\infty}$ or $n_{\mathrm{D}^{2}}$. As the $n_{\mathrm{D}^{2}}$ of ice calculated from Clausius and Mossotti's relation increases (Johari, 1976) from $\mathrm{I} .715$ at $273 \mathrm{~K}$ to 1.724 at $200 \mathrm{~K}$, but $\epsilon_{\infty}$ decreases from 3.20 to 3.14 (Fig. 7) in the same temperature range, it is apparent that $m$ should be given by either $\left(\epsilon_{\infty}+2\right) / 3$, or else a quantity that decreases with temperature, if $A$ in Equation (7) were to remain constant.

\subsection{The limiting high-frequency relative permittivity}

The values of $\epsilon_{\infty}$ were obtained by a graphical extrapolation of the high-frequency end of the complex-plane plots of $\epsilon^{\prime}$ and $\epsilon^{\prime \prime}$. Reliable values could be obtained only at temperatures where $\epsilon^{\prime \prime}$ at $\mathrm{I}$ oo $\mathrm{kHz}$ was less than o. I. This condition was satisfied at temperatures below $235 \mathrm{~K}$. The $\epsilon_{\infty}$ values for eight samples measured parallel to the $c$-axis and six perpendicular to the $c$-axis are given in Figure 7 . The values at temperatures above $240 \mathrm{~K}$, which are taken from the literature (Johari, I976), extrapolate to those below $253 \mathrm{~K}$ in a manner similar to that seen in polycrystalline ice (Gough, 1972). This indicates that our present measurements of $\epsilon_{\infty}$ perpendicular to the $c$-axis are consistent with the previous ones (Johari, I976), although the equipment and the frequencies used in obtaining the $\epsilon_{\infty}$ values in the two measurements differ. It is evident in Figure 7 that the $\epsilon_{\infty}$ of ice parallel and perpendicular to the $c$-axis are the same within $\pm 0.5 \%$.

The reason for a decrease in $\epsilon_{\infty}$ with temperature of polycrystalline ice has been a subject of discussion earlier (Gough, I972; Johari, I976; Johari and Jones, 1976[b]). In view of the observed isotropic behaviour of $\epsilon_{\infty}$ of ice, the discussion for single crystals of ice should be similar.

\subsection{The average relaxation time}

The average relaxation time $\tau_{\mathrm{av}}$ was calculated from the frequency of maximum loss using the equation $\tau_{\mathrm{av}}=\left(2 \pi f_{\mathrm{m}}\right)^{-1}$. The $f_{\mathrm{m}}$ values were obtained by plotting $\epsilon^{\prime \prime}$ against the 
logarithm of frequency on a large scale and interpolating. The $\tau_{\mathrm{av}}$ for both the orientations of ice agreed, to within $\pm 5 \%$, with Wörz and Cole's (1969) data and, at temperatures above 248 K, with Von Hippel and others' (197I), Ruepp's (1973), and Taubenberger's (1973) data.

According to Eyring's rate-process theory, the relaxation time for a molecular reorientation is given by,

$$
\tau_{\mathrm{av}}=\left(\tau_{0} / T\right) \exp \left(E^{\star} / R T\right)
$$

where the pre-exponential factor $\tau_{0}$ is given by,

$$
\tau_{0}=(h / e k) \exp \left(-S^{\star} / R\right),
$$

$h$ is Planck's constant, $k$ is the Boltzmann factor, $e$ is the transmission coefficient, $S^{\star}$ and $E^{\star}$ are the entropy and energy of activation respectively, and $R$ is the gas constant. The product of $\tau_{\mathrm{av}}$ and temperature is logarithmically plotted against the reciprocal temperature in

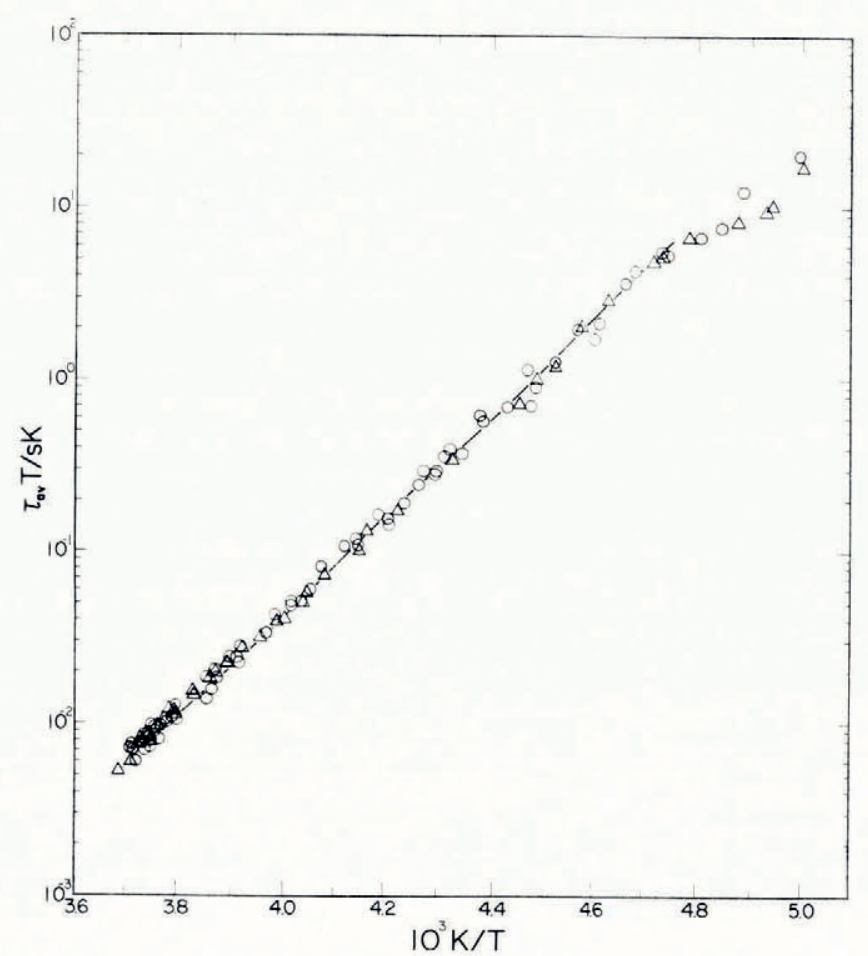

Fig. 8. The variation of the product of the average relaxation time and temperature of ice plotted logarithmically against reciprocal temperature. $\bigcirc$, parallel to the c-axis; $\triangle$, perpendicular to the c-axis.

Figure 8. The plot is linear in the temperature range $210-270 \mathrm{~K}$. The values of $\tau_{0}$ and $E^{\star}$ with standard deviation obtained from the least-square treatment of data for each of the two orientations and of the data for all samples and orientations are given in Table III.

The combined effect of the difference of $\tau_{\mathrm{av}}, \epsilon_{0}$, and $\epsilon_{\infty}$ as a function of temperature between the various samples measured for the two orientations can be seen in Figure 9 , where $\epsilon^{\prime}$ and $\epsilon^{\prime \prime}$ at $0 . \mathrm{I} \mathrm{kHz}$ are plotted against the temperature. At high temperatures the deviation from the average plot indicates the uncertainty in the measurement of $\Delta \epsilon$ for different samples and at low temperatures the uncertainty in $\tau$ values which contribute by a term $\left(\mathrm{I}+\omega^{2} \tau^{2}\right)$ in $\epsilon^{\prime}$ and $\omega \tau /\left(\mathbf{I}+\omega^{2} \tau^{2}\right)$ in $\epsilon^{\prime \prime}$. It is evident from Figures 8 and 9 that the relaxation time of ice is also isotropic between 210 and $27 \mathrm{I} \mathrm{K}$. 


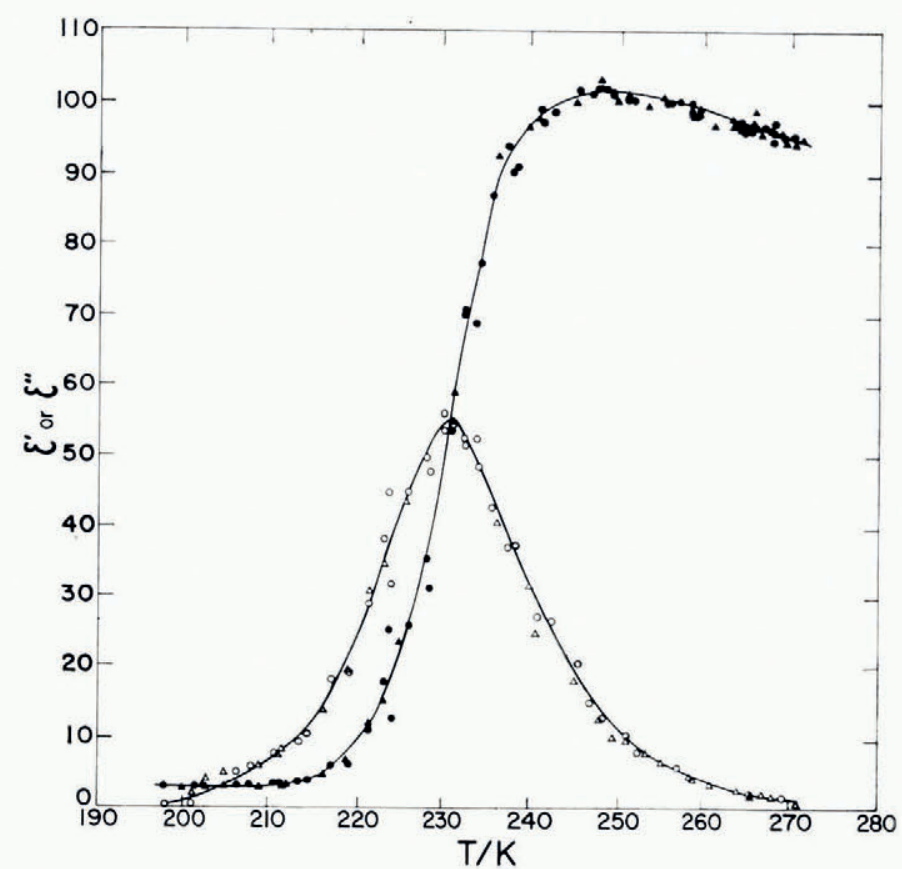

Fig. 9. The relative permittivity and loss of ice at o.I $\mathrm{kHz}$ plotted against temperature to show the combined effect of variation in $\tau_{\mathrm{av}}, \epsilon_{0}$ and $\epsilon_{\infty}$ on the orientation of the sample. $\bigcirc$, parallel to the c-axis, and $\triangle$, perpendicular to the c-axis. Open data points are for $\epsilon^{\prime \prime}$ and filled data points for $\epsilon^{\prime}$.

The $\tau_{\mathrm{av}}$ of ice for both the orientations follows the Eyring equation from $27 \mathrm{I}$ to 2 I $0 \mathrm{~K}$ with $E^{\star}=5^{\mathrm{I}} \pm 2 \mathrm{~kJ} \mathrm{~mol}^{-1}$ and $S^{\star}={ }_{1} 8 \pm 2 \mathrm{~J} \mathrm{~mol}^{-1} \mathrm{~K}^{-1}$, below which temperature the data show a large scatter and a trend towards a slope giving lower values of $E^{\star}$. The change towards a decreasing slope appears in Wörz and Cole's (1969) plot at $c .240 \mathrm{~K}$, in Von Hippel and other's (197I) plot at $c .250 \mathrm{~K}$ and in Ruepp's (1973) plot at $c .230 \mathrm{~K}$, although these workers have plotted $\tau_{\mathrm{av}}$, rather than $\tau_{\mathrm{av}} T$, against $T^{-\mathrm{r}}$. It is well recognized that the concentration of lattice defects has no effect on the steady-state polarization ultimately established, which is an equilibrium quantity: they provide only the mechanism by which it is established and their concentration determines the rate of establishment. A small amount of substitutionally or interstitially present impurity in zone-refined ice may produce orientational defects which at $T<2$ I0 $\mathrm{K}$ are more numerous than those produced by the thermal motion of water molecules in an ideal lattice and thus may cause $E^{\star}$ and $S^{\star}$ to become appreciably smaller. Gough and Davidson (I970) found that $\tau_{\mathrm{av}}$ of polycrystalline ice, obtained from depressurizing ice II, was much higher than that of any sample of ice obtained by freezing water. The $\tau_{\mathrm{av}}$, however, decreased by several orders of magnitude when the ice was annealed. They proposed that the decrease in $\tau_{\mathrm{av}}$ on annealing was caused by the dissolution of impurities, which had separated from hexagonal ice during its transformation to ice II and back into the hexagonal ice. It is noteworthy that impurities are thought to be much less soluble in the high-pressure phases of ice than in hexagonal ice, and indeed ice VI (Johari and Whalley, 1976) and ice VII (Johari and others, 1974) show no decrease in $E^{\star}$ with temperature. According to this interpretation, our zone-refined ice contains less impurity-produced orientational defects than any other sample of ice reported in the literature.

Gränicher (I969) and Bilgram and Gränicher (I974), after considering the $\tau_{\text {av }}$ and the d.c. conductivity together, have proposed that a decrease in $E^{\star}$ with temperature is caused by a 
change in the relaxation mechanism from the one dominated by diffusion of orientational defects to the one dominated by diffusion of intrinsic ionic defects. In this view the decrease in $E^{\star}$ is intrinsic to the nature of ice, although no high-pressure phase of ice has shown this behaviour. Furthermore, the change in the relaxation mechanism occurs at a temperature when $\sigma_{ \pm} / p=\sigma_{\mathrm{DL}} / q$ (Bilgram and Gränicher, I974), where $\sigma_{ \pm}$and $\sigma_{\mathrm{DL}}$ are the conductivity due to ionic and Bjerrum defects and $p$ and $q$ are the effective charge associated with the defects, respectively. At this temperature the $\epsilon_{0}$ should reach a minimum value given by, $\epsilon_{0} \approx \epsilon_{\infty}$ (Jaccard, I 965 ). This has not been observed for the zone-refined ice by us, or by other workers. It seems, therefore, more plausible that a decrease in $E^{\star}$ with temperature is caused by the impurity-generated orientational defects rather than the intrinsic ionic defects in ice.

\subsection{The effect of ageing}

As shown in Table I, the stock from which the ice samples were obtained was I-8 years old, yet their $\epsilon^{\prime}$ and $\epsilon^{\prime \prime}$ decreased on annealing when contained in the dielectric cell. A number of samples of ice, of both the orientations, were stored at $253 \pm 2 \mathrm{~K}$ for periods ranging from one to five weeks. Measurements made after this period showed a decrease by as much as $50 \%$ in $\epsilon^{\prime \prime}$ at the frequency closest to the low-frequency intercept of the complex-plane plot, an increase of $0.5 \%$ in $\tau_{\mathrm{av}}$, but no change in $\Delta \epsilon$. One sample of ice oriented with the $c$-axis perpendicular to the electric field, contained in the Type KMT Capacitor, was kept at $253 \pm 2 \mathrm{~K}$ for I I weeks after the first measurement. Its $\Delta \epsilon$ and $\tau_{\mathrm{av}}$ measured after this period showed a similar effect.

Taubenberger (1973) has reported that the $\Delta \epsilon$ of ice at $25^{8} \mathrm{~K}$ measured perpendicular to the $c$-axis decreased by $\mathrm{I} \%$, the $\epsilon_{\infty}$ increased by $10 \%$ and the $\tau$ decreased by $8 \%$, when the ice contained between the electrodes was annealed at $258 \mathrm{~K}$ for I $795 \mathrm{~h}$. Another sample measured parallel to the $c$-axis at $248 \mathrm{~K}$, showed no change in $\Delta \epsilon$ and $\tau$ but an increase in $\epsilon_{\infty}$ of $2 \%$, when annealed for $\mathrm{I} \mathrm{IO}$ h at that temperature. In our experience, the values of $\epsilon_{\infty}$ at $258 \mathrm{~K}$ extrapolated from measurements made only at kilohertz frequencies are somewhat uncertain, and little information is given by Taubenberger regarding the contribution to $\epsilon^{\prime}$ and $\epsilon^{\prime \prime}$ from space charge effects at low-frequencies. The change in $\tau$ in our measurement is apparently due to a reduction in the space charge polarization, as discussed in Section 4.I. Such changes are not likely to be intrinsic to ice.

\section{REFERENCES}

Bernal, J. D., and Fowler, R. H. 1933. A theory of water and ionic solution, with particular reference to hydrogen and hydroxyl ions. Fournal of Chemical Physics, Vol. 1, No. 8, p. 515-48.

Bilgram, J. H., and Gränicher, H. 1974. Defect equilibria and conduction mechanism in ice. Physics of Condensed Matter, Vol. 18 , No. 4, p. 275-9i.

Bjerrum, N. r 95 I. Structure and properties of ice. Kongelige Danske Videnskabernes Selskab. Matematisk-fysiske Meddelelser, Bd. 27, Nr. I.

Chan, R. K., and others. 1965. Effect of pressure on the dielectric properties of ice I, [by] R. K. Chan, D. W. Davidson and E. Whalley. Journal of Chemical Physics, Vol. 43, No. 7, p. 2376-83.

Clough, S. A., and others. 1973. Dipole moment of water from Stark measurements of $\mathrm{H}_{2} \mathrm{O}, \mathrm{HDO}$ and $\mathrm{D}_{2} \mathrm{O}$, [by] S. A. Clough, Y. Bears, G. P. Klein and L. S. Rothman. Journal of Chemical Physics, Vol. 59, No. 5, p. 2254-59.

Davidson, D. W., and Wilson, G. J. 1963. The low-frequency dielectric properties of ethylene oxide and ethylene oxide hydrate. Canadian Journal of Chemistry, Vol. 41, No. 6, p. ${ }^{1} 4^{24} 4^{-34}$.

Fröhlich, H. 1949. Theory of dielectrics; dielectric constant and dielectric loss. Oxford, Clarendon Press. (Monographs

on the Physics and Chemistry of Materials.)
Gobush, W., jr., and Hoeve, C. A. J. 1972. Calculation of the dielectric correlation factor of cubic ice. Fournal of Chemical Physics, Vol. 57 , No. 8, p. 3416-21.

Gough, S. R. 1972. A low temperature dielectric cell and the permittivity of hexagonal ice to 2 K. Canadian fournal of Chemistry, Vol. 50, No. 18, p. 3046-51. 
Gough, S. R., and Davidson, D. W. 1970. Dielectric behaviour of cubic and hexagonal ices at low temperatures. Fournal of Chemical Physics, Vol. 52, No. 10, p. 5442-49.

Gough, S. R., and others. 1973. Dielectric properties of some clathrate hydrates of structure II, [by] S. R. Gough, R. E. Hawkins, B. Morris and D. W. Davidson. Journal of Physical Chemistry, Vol. 77, No. 25, p. 2969-76.

Gränicher, H. 1969 . Review on problems of physics of ice. (In Riehl, N., and others, ed. Physics of ice: proceedings of the international symposium on physics of ice, Munich, Germany, 9-14 September 1968. Edited by N. Riehl, B. Bullemer, H. Engelhardt. New York, Plenum Press, p. I-18.)

Gränicher, H., and others. I955. Dielektrische Eigenschaften des Eises bei sehr tiefen Frequenzen und der Einfluss eines Vorfeldes, von H. Gränicher, C. Jaccard, P. Scherrer und A. Steinemann. Helvetica Physica Acta, Vol. 28, Fasc. 4, p. 300-03.

Haida, O., and others. I 974 . Calorimetric study of the glassy state. X. Enthalpy relaxation at the glass-transition temperature of hexagonal ice, [by] O. Haida, T. Matsuo, H. Suga and S. Seki. Journal of Chemical Thermodynamics, Vol. 6 , No. 9 , p. $815^{-25}$.

Hollins, G. T. I964. Configurational statistics and the dielectric constant of ice. Proceedings of the Physical Society, Vol. 84 , Pt. 6, p. 1001-16.

Humbel, F., and others. I953. Anisotropie der Dielektrizitätskonstante des Eises, von F. Humbel, F. Jona und P. Scherrer. Helvetica Physica Acta, Vol. 26, Fasc. 1, p. 1 7-32.

Jaccard, C. 1965. Mechanism of electrical conductivity in ice. Annals of the New York Academy of Sciences, Vol. 125, Art. 3, p. 390-400.

Johari, G. P. 1976. The dielectric properties of $\mathrm{H}_{2} \mathrm{O}$ and $\mathrm{D}_{2} \mathrm{O}$ ice $\mathrm{Ih}$ at $\mathrm{MHz}$ frequencies. Fournal of Chemical Physics, Vol. 64, No. 10, p. 3998-4005.

Johari, G. P., and Jones, S. J. $1976[\mathrm{a}]$. Dielectric properties of polycrystalline $\mathrm{D}_{2} \mathrm{O}$ ice $\mathrm{Ih}$ (hexagonal). Proceedings of the Royal Society of London, Ser. A, Vol. 349, No. 1659, p. 467-95.

Johari, G. P., and Jones, S. J. I976[b]. Infrared polarisability of hexagonal ice. Nature, Vol. 263, No. 5579, p. $672-73$.

Johari, G. P., and Whalley, E. 1973. Orientational order in ice I, V, VI and VII. (In Whalley, E., and others, ed. Physics and chemistry of ice: papers presented at the Symposium on the Physics and Chemistry of Ice, held in Ottawa, Canada, 14-18 August, 1972. Edited by E. Whalley, S. J. Jones, L. W. Gold. Ottawa, Royal Society of Canada, p. 278-82.)

Johari, G. P., and Whalley, E. 1976. Dielectric properties of ice VI at low temperatures. Journal of Chemical Physics, Vol. 64, No. I i, p. 4484-89.

Johari, G. P., and others. I974. Dielectric properties of ice VII and VIII and the phase boundary between ice VI and VII, [by] G. P. Johari, A. Lavergne and E. Whalley. Journal of Chemical Physics, Vol. 6r, No. Io, p. $4292-300$.

Kirkwood, J. G. 1939. The dielectric polarisation of polar liquids. Fournal of Chemical Physics, Vol. 7, No. 9, p. $911-28$.

Kirkwood, J. G. 1940. On phase changes in crystals arising from hindered molecular rotation. Fournal of Chemical Physics, Vol. 8, No. 2, p. 205-12.

Lonsdale, K. 1958. The structure of ice. Proceedings of the Royal Society of London, Ser. A, Vol. 247, No. 1251, p. 424-34.

McCammon, R. D., and Work, R. N. 1965. Measurement of the dielectric properties and thermal expansion of polymers from ambient to liquid helium temperatures. Review of Scientific Instruments, Vol. 36, No. 8, p. 1 169-73.

Maeno, N. 1973. Studies of dielectric properties of ice grown from KCl solution. Contributions from the Institute of Low Temperature Science, Hokkaido University (Sapporo), Ser. A, No. 25, p. I-47.

Nagle, J. F. 1974. Dielectric constant of ice. Journal of Chemical Physics, Vol. 61, No. 3, p. $88_{3}-88$.

Onsager, L., and Dupuis, M. 1962. The electrical properties of ice. (In Pesce, B., ed. Electrolytes: proceedings of an international symposium on electrolytes, held in Trieste, June 1959. Oxford, etc., Pergamon Press, p. 27-46.)

Pauling, L. 1935. The structure and entropy of ice and of other crystals with some randomness of atomic arrangement. Journal of the American Chemical Society, Vol. 57, No. 1 2, p. 2680-84.

Rahman, A., and Stillinger, F. H. 1972. Proton distribution in ice and the Kirkwood correlation factor. Fournal of Chemical Physics, Vol. 57, No. 9, p. 4009-1 7 .

Ruepp, R. 1973. Electrical properties of ice Ih single crystals. (In Whalley, E., and others, ed. Physics and chemistry of ice: papers presented at the Symposium on the Physics and Chemistry of Ice, held in Ottawa, Canada, I $4^{-1} 8$ August 1972. Edited by E. Whalley, S. F. Jones, L. W. Gold. Ottawa, Royal Society of Canada, p. 179-86.)

Ruepp, R., and Käss, M. I969. Dielectric relaxation, bulk and surface conductivity of ice single crystals. (In Riehl, N., and others, ed. Physics of ice: proceedings of the international symposium on physics of ice, Munich, Germany, 9-14 September 1968. Edited by . . Riehl, B. Bullemer, H. Engelhardt. New York, Plenum Press, p. 555-61.)

Stillinger, F. H., and Cotter, M. A. 1973. Local orientational order in ice. Fournal of Chemical Physics, Vol. 58 , No. 6, p. $2532-4$ i.

Taubenberger, R. 1973. Aging effects of electrical properties of ice Ih single crystals. (In Whalley, E., and others, ed. Physics and chemistry of ice: papers presented at the Symposium on the Physics and Chemistry of Ice, held in Ottawa, Canada, I4-18 August, 1972 . Edited by E. Whalley, S. F. Jones, L. W. Gold. Ottawa, Royal Society of Canada, p. $187-93$.)

Von Hippel, A. R., and others. 1971. Transfer of protons through "pure" ice Ih single crystals. I. Polarisation spectra of ice Ih, [by] A. [R.] Von Hippel, D. B. Knoll and W. B. Westphal. Fournal of Chemical Physics, Vol. 54 , No. I, p. $134-44$.

Wilson, G. J., and Davidson, D. W. 1963. Dielectric evidence for acetone hydrate. Canadian Journal of Chemistry, Vol. 41, No. 2, p. 264-73. Wörz, O., and Cole, R. H. 1969. Dielectric properties of ice I. Journal of Chemical Physics, Vol. 51, No. 4,
p. 1546-50. 


\section{DISCUSSION}

G. Noll: Following the discussion about the anisotropy of ice Ih during the Symposium on Physics and Chemistry of Ice in Ottawa, 1972, Ruepp carried out dielectric measurements parallel and perpendicular to the electric field with the same monocrystal. He used a cylindrical sample with $c$-axis perpendicular to the cylinder axis. This elegant method avoids the difficulties and errors associated with the preparation of different samples. Rotation of the crystal in the field showed a clear anisotropy, but it was smaller than the value given by Humbel and others (1953).

R. TAubenberger: Did you account for the error of $2 \sigma_{0} \tau / \epsilon_{0}$ one commits in $\epsilon_{0}$ by extrapolating a Cole-Cole semicircle for a Debye dispersion plus a constant $\sigma_{0}$ ? Could you give your $\sigma_{0}(T)$ values or at least values of $\omega \epsilon^{\prime \prime}$ minima you found in your Cole-Cole representations?

G. P. JoharI: Yes, we did this by restricting the range by which $\epsilon^{\prime}$ was to be extrapolated to obtain $\epsilon_{0}$, although we doubt that the error in such analyses are entirely due to a non-zero value of $\sigma_{0}$, because there is a contribution from the space-charge polarization as well. The criterion we established for our analysis was that $\epsilon^{\prime \prime}$ at the frequency nearest to the lowfrequency end of the axis should be four or less, otherwise the extrapolated $\epsilon_{0}$ would be in error by more than $0.5 \%$. Some values of $\omega \epsilon^{\prime \prime}$ which you wish to know can be calculated from Figure 3 in the paper.

TAubenberger: Did you not allow for an increasing width of relaxation times distribution with your $\epsilon_{0}$ extrapolation method on going to lower temperatures so that your $\epsilon_{0}(T)$ is not directly comparable to what one gets on fitting for all temperatures to a simple Debye dispersion?

JohARI: The $\epsilon_{0}$ was obtained from an extrapolation of the complex-plane plots I had shown. In these plots $\epsilon^{\prime}$ for the lowest frequency closest to the axis is not significantly different from the extrapolated $\epsilon_{0}$. The increase in the half-width of the $\epsilon^{\prime \prime}-\log f$ plots with decreasing temperature thus does not affect the accuracy of $\epsilon_{0}$. Our $\epsilon_{0}(T)$ values are not strictly the same as ones obtained by assuming a simple Debye dispersion at temperatures where the $\epsilon^{\prime \prime}-\log f$ plots are considerably broader than required by the Debye equation.

TAubenberger: Could you comment on the relatively small activation energy for $\tau$ you obtained, corresponding to $0.527 \mathrm{eV}$ in your whole temperature range, as compared to the usual $0.5^{8}$ to $0.6 \mathrm{I} \mathrm{eV}$ for higher temperatures lowering when $T<c$. $240 \mathrm{~K}$ depending on $\sigma_{0}$ behaviour?

JoHARI: The activation energy we obtained is $5^{1} \pm 2 \mathrm{~kJ} \mathrm{~mol}^{-1}$ or $0.53 \pm 0.02 \mathrm{eV}$. This value is $c$. $0.02 \mathrm{eV}$ lower than the Arrhenius energy corresponding to our plot, so, if you were to compare our value with the literature, you should use $0.55 \pm 0.02 \mathrm{eV}$. I believe a comparison with the literature values would not be meaningful for two reasons: (I) we do not know the uncertainty in the literature values of Arrhenius energy and (2) the values in the literature were obtained, as you correctly indicate, from measurements made over a temperature range of $c .33 \mathrm{~K}$ but our value comes from a larger temperature range and even larger $\mathcal{T}^{-1}$ range.

TAUBENBERGER: Did you not see any change in capacitance due to flow of your samples which were under 3-4 bars uniaxial stress sometimes for several weeks at relatively high temperatures?

JOHARI: We observed no change in capacitance over a period of weeks when the sample was under a uniaxial stress of $3-4$ bars.

TAubenberger: As to Ruepp's data (1973); though this author does not decide definitely for anisotropy, his data on his figure 3 nevertheless strongly suggest also significant anisotropy as do the data of Von Hippel and others (197I), thus confirming at least qualitatively our own findings of an anisotropy $>10 \%$, confirming the early data of Humbel and others ( 1953 ). 